\title{
CONSOLIDATION OF PSYCHOPHYSIOLOGY AS A SCIENTIFIC DISCIPLINE, 1930 -1964: A HISTORICAL NOTE
}

\author{
Authors: Socorro Rodríguez Holguín, Fernando Cadaveira
}

This is the peer reviewed version of the following article: Rodríguez Holguín, S. \& Cadaveira, F. (2002). Consolidation of psychophysiology as a scientific discipline, 1930 -1964: A historical note. Psychophysiology, 39(5), 619-624. doi: 10.1111/1469$\underline{8986.3950619}$

This article may be used for non-commercial purposes in accordance with Willey and the Society for Psychophysiological Research terms and conditions for use of self-archived versions. 


\title{
Consolidation of psychophysiology as a scientific discipline, 1930 -1964: A historical note.
}

\author{
Socorro Rodríguez Holguín ${ }^{1}$, Fernando Cadaveira \\ Departamento de Psicoloxía Clínica e Psicobioloxía, Universidade de Santiago de \\ Compostela, Galiza, Spain
}

\begin{abstract}
The ground covered by psychophysiology throughout the decades prior to its constitution as an independent discipline has not been well documented, despite its historical interest. A bibliometric study of the research published in scientific journals by 66 of the most relevant psychophysiologists from 1930 to 1964, analyzing the contents of the records indexed in the PsycINFO database, gives us an image of the state of the emergent discipline during that period. This study reveals that this was a period of consolidation, marked by the refinement of instruments and procedures, the characterization of measurements, and the establishment of the basic relationships between physiological and psychological variables, the development and validation of basic constructs such as activation, or interest in the study of psychopathology. In these years the foundations of psychophysiology were laid, leading to the formalization of the discipline at the end of the period.
\end{abstract}

Descriptors: Historical analysis, Bibliometry, Psychophysiology

There is common agreement in considering the early 1960s as the period of the formalization of psychophysiology as an independent discipline. The constitution of the Society for Psychophysiological Research in 1960, and the publication of the first volume of Psychophysiology, in 1964, are the main events that define this process. Nevertheless, the discipline had been in a condition of gradual consolidation throughout previous decades. In the first volume of Psychophysiology, Ax (1964a) and Darrow (1964) offered a short description of the state of the discipline at that time, and Stern (1964) provided a concise and still valid definition of psychophysiology and the guidelines concerning the research of interest to psychophysiologists. However, as far as we know there are no historical reviews which characterize the period when psychophysiology was progressively configured as a discipline, and this is the aim of the present bibliometric study.

\footnotetext{
${ }^{1}$ Address reprint requests to: Socorro Rodríguez Holguín, Departamento de Psicoloxía Clínica e Psicobioloxía, Facultade de Psicoloxía, Universidade de Santiago de Compostela, Santiago de Compostela, E-15782, Galicia, Spain. E-mail: rodrifguez.holguin@usc.es.

Received May 16, 2001; Accepted February 15, 2002
} 
By the beginning of the 1930s, the basic techniques for psychophysiological recordings were available, and a period started that was characterized by a progressive consolidation of psychophysiological studies. In 1929, Berger (192901969) reported the discovery of the human electroencephalogram and Darrow published two important papers: a review of more than 30 empirical studies assessing the effects of sensory and ideational stimuli on physiological responses (Darrow, 1929a), and an empirical study of the effects of more than 100 different stimuli on those responses using a sample of 70 subjects (Darrow, 1929b). In subsequent decades, psychophysiology would become increasingly present in psychological research, demonstrated by the inclusion of chapters about body changes during emotion or the psychogalvanic reflex in Woodworth's (1938) classic manual Experimental Psychology. Psychophysiologists would cover more ground, improving recording instruments, refining and standardizing protocols, and laying the empirical and theoretical foundations of the relationships between physiological variables and psychological processes.

Among the outstanding events of this period are the theoretical developments in activation and related concepts, such as response stereotypy (Duffy, 1957; Lacey \& Lacey, 1958; Malmo, 1959; Malmo \& Shagass, 1949); the renewal of interest in the study of emotions (Ax, 1953); attempts at EEG characterization (the American Electroencephalographic Society was formed in 1947), and, for methodological issues, the progressive incorporation of computer analysis and the development of evoked potential techniques (Dawson, 1947, 1954), which made possible the publication, at the end of the period analyzed, of the first papers describing cognitive event-related potential components, contingent negative variation (Walter, Cooper, Aldridge, McCallum, \& Winter, 1964), and P300 (Sutton, Braren, Zubin, \& John, 1965). To characterize this period, we have carried out a bibliometric study of the reports from the most important authors that appeared in scientific journals between 1930 and 1964.

\section{Method}

The lower limit of the selected period $(1930-1964)$ is the publication of the referred works by Berger and Darrow and the increased use of polygraphs in laboratories. The upper limit is determined by the publication of the first international journal completely dedicated to this discipline, Psychophysiology.

The authors selected for this study are those who published in volume 1 of Psychophysiology, those with chapters in the handbooks and monographs published until the early 1970s (Brown,1967; Greenfield \& Sternbach, 1972; Sternbach, 1966; Venables \& Christie, 1975), and those referred to as relevant researchers by historical reviews (Ax, 1964b; Niedermeyer, 1993; Thompson \& Robinson, 1979). Also included were authors of classic studies cited in specialized publications even today, and researchers who were recognized by the Society for Psychophysiological Research as presidents of the Society or honored with the Society's "Award for Distinguished Contributions to Psychophysiology."

The publications of these authors were screened by the computerized database PsycINFO (edited by the American Psychological Association) throughout the selected 
years; papers published in the first volume of Psychophysiology were excluded. Only articles published in journals were included, as the database does not contain an exhaustive tabulation of books, chapters, or conferences from this period. Publications composed only of an abstract (those labeled in the database with the note "Source contains an abstract only") were excluded from the study.

Multiple records of the same work as a result of papers signed by two or more authors were controlled. In these cases, the papers were assigned to only one of the authors. Finally, the study included 66 authors, listed in Table 1.

Table 1. List of Authors of Studies in Psychophysiology Published in Journals between 1930 and 1964

(PsyclNFO, 1887-1970).

\begin{tabular}{|c|c|c|c|c|c|}
\hline Author & $\begin{array}{l}\text { Period of } \\
\text { publications }\end{array}$ & $\begin{array}{c}\text { Number of papers } \\
\text { in } \\
\text { psychophysiology }\end{array}$ & Author & $\begin{array}{l}\text { Period of } \\
\text { publications }\end{array}$ & $\begin{array}{l}\text { Number of papers } \\
\text { in } \\
\text { psychophysiology }\end{array}$ \\
\hline Acker, C. W. (1) & $1962-1963$ & 2 & Lacey, B. C. (1) (3) & $1941-1964$ & 3 \\
\hline Adrian, E. D. (2) (3) & 1939-1963 & 4 & Lacey, J. I. (2) (3) & $1947-1963$ & 7 \\
\hline Aserinsky, E. (2) & $1953-1955$ & 3 & Lader, M. (1) & $1962-1964$ & 2 \\
\hline Ax, A. F. (1) (3) & $1946-1964$ & 16 & Landis, C. (2) & $1930-1960$ & 15 \\
\hline Berger, H. (3) & $1930-1940$ & 13 & Lang, P. J. (1) (3) & 1958-1963 & 2 \\
\hline Berger, L. (1) & $1958-1964$ & 1 & Lindsley, D. B. (2)(3) & $1931-1964$ & 18 \\
\hline Block, J. D. (2) & $1962-1964$ & 3 & Loomis, A. L. (2) (3) & $1931-1939$ & $10^{c}$ \\
\hline Brazier, M. A. (2) & 1938-1964 & 7 & Lubin, A. (1) & $1951-1964$ & 5 \\
\hline Brozek, J. (1) & $1947-1964$ & 4 & Lykken, D. T. (1) (3) & $1956-1963$ & 5 \\
\hline Darrow, C. W. (1)(2)(3) & $1930-1964$ & 40 & Malmo, R. B. (1) (2) & $1940-1963$ & 30 \\
\hline Davis, J. F. (1) & $1950-1962$ & 2 & Martin, I. (1) & $1956-1964$ & 7 \\
\hline Davis, R. C. (2) (3) & $1930-1963$ & 42 & Obrist, P. (3) & $1958-1964$ & 5 \\
\hline Dawson, G. D. (3) & $1954-1960$ & 3 & Oken, D. (2) & $1956-1964$ & 9 \\
\hline Dement, W. (2) & $1955-1964$ & 7 & Orne, M. T. (1) & $1951-1964$ & 3 \\
\hline Docter, R. F. (1) & $1956-1964$ & 3 & Razran, G. H. S. (2) & $1933-1961$ & 14 \\
\hline Donchin, E. (3) & $1963-1964$ & 2 & Shagass, C. (1) (3) & $1941-1964$ & 13 \\
\hline Duffy, E. (1) (2) (3) & $1946-1962$ & 4 & Shapiro, D. (3) & 1949-1964 & 5 \\
\hline Dykman, R. A. (1) & $1951-1964$ & 5 & Shearn, D. W. (1) & $1961-1962$ & 2 \\
\hline Edelberg, R. (1) (3) & $1954-1963$ & 7 & Sokolov, E. N. (2) (3) & $1951-1964$ & 14 \\
\hline Engel, B. T. (1) (3) & $1957-1962$ & 2 & Stein, M. (1) & 1943-1964 & 1 \\
\hline Forbes, T. W. (1) & $1930-1960$ & 12 & Stern, J. A. (1) (3) & $1954-1964$ & 10 \\
\hline Freeman, G. L. (3) & $1930-1963$ & 23 & Sternbach, R. A. (1) & $1960-1964$ & 6 \\
\hline Gibbs, F. A. (2) & 1935-1962 & 16 & Sutherland, G. F. (1) & $1934-1964$ & 4 \\
\hline Goldstein, I. B. (1) & $1963-1964$ & 2 & Travis, L. E. (2) & $1930-1945$ & 21 \\
\hline Graham, D. T. (1) (3) & $1944-1962$ & 6 & Tursky, B. (3) & $1951-1964$ & 2 \\
\hline Graham, F. K. (3) & $1943-1964$ & 2 & Venables, P. H. (1)(3) & $1956-1964$ & 10 \\
\hline Greenfield, N. S. (1) & $1956-1963$ & $5^{b}$ & Walter, W. G. (2) & 1949-1964 & 7 \\
\hline Grings, W. W. (3) & $1942-1964$ & 13 & Welford, N. T. (1) & 1949-1963 & 4 \\
\hline Hess, E. H. (1) & $1950-1964$ & 2 & Wenger, M. A. (1) (3) & 1933-1962 & 21 \\
\hline Jasper, H. H. (3) & $1930-1962$ & 13 & Wilcott, R. C. (1) & 1953-1963 & 13 \\
\hline Johnson, L. C. (1) (3) & $1955-1964$ & 7 & Wilder, J. (2) (3) & $1947-1962$ & 3 \\
\hline Kaplan, S. (1) & $1962-1964$ & 4 & Wolf, S. (1) & $1941-1964$ & 14 \\
\hline Kleitman, N. (2) & $1930-1963$ & 9 & Wolff, H. G. (2) & 1932-1959 & 7 \\
\hline
\end{tabular}


Only those studies falling into the field of psychophysiology -according to the description of the field given by Stern (1964)- were selected, and those by the same authors but with no psychophysiological content -mainly dealing with experimental psychology, physiology, or neurophysiology- were excluded.

Using these criteria, 576 papers were finally selected. Abstracts were reviewed considering the topic of research, the physiological system assessed, and the samples studied.

\section{Results}

\section{General Aspects}

Table 1 shows the variability in the number of publications between authors. Only 9 of the 66 authors have more than 15 papers in the field of psychophysiology, and another 13 authors published between 10 and 15 papers (Figures 1 and 2).

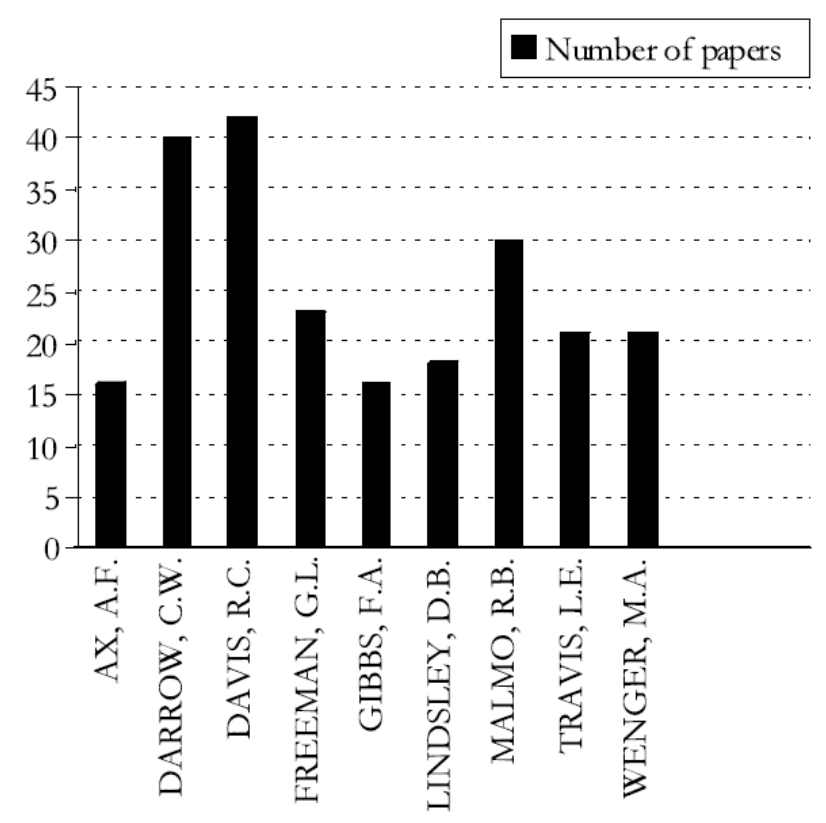

Figure 1. Authors with more than 15 papers published in psychophysiology.

As regards the evolution in the number of studies published by these authors, Figure 3 presents the distribution in 5-year intervals. It may be seen that World War II and the postwar period interrupted growth, as occurs in most areas of scientific research, which resumed in the 1950s, and gained momentum after the formation of the Society for Psychophysiological Research in 1960.

The type of reports published during the period reviewed shows a clear predominance of empirical studies over theoretical studies or those reviewing or integrating results. Excluding the methodological reports -which represent $12.3 \%$ of the total number of papers analyzed- $88 \%$ of the articles are empirical, compared to only 
$12 \%$ with theoretical Oreview contents. This is a common characteristic in the early days of investigation in any field.

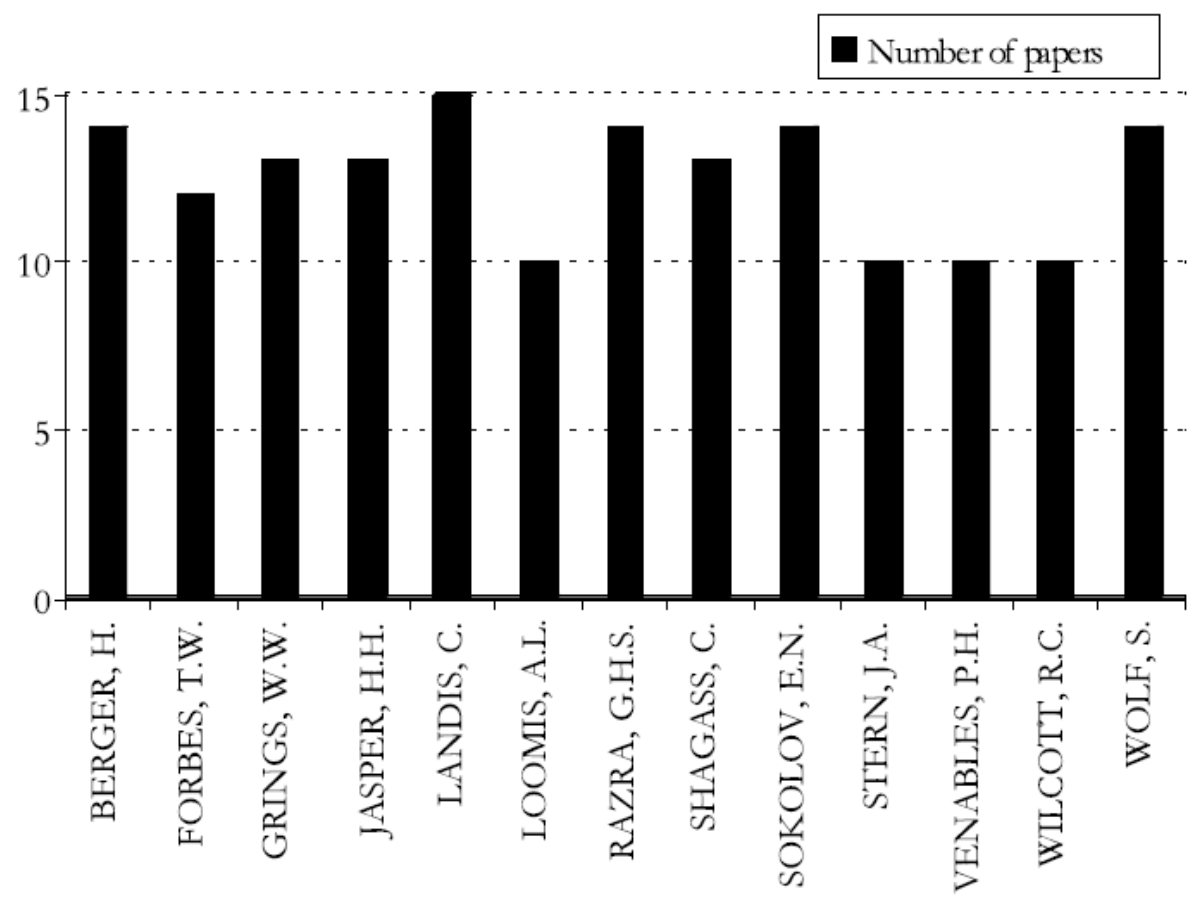

Figure 2. Authors who published between 10 and 15 papers in psychophysiology.

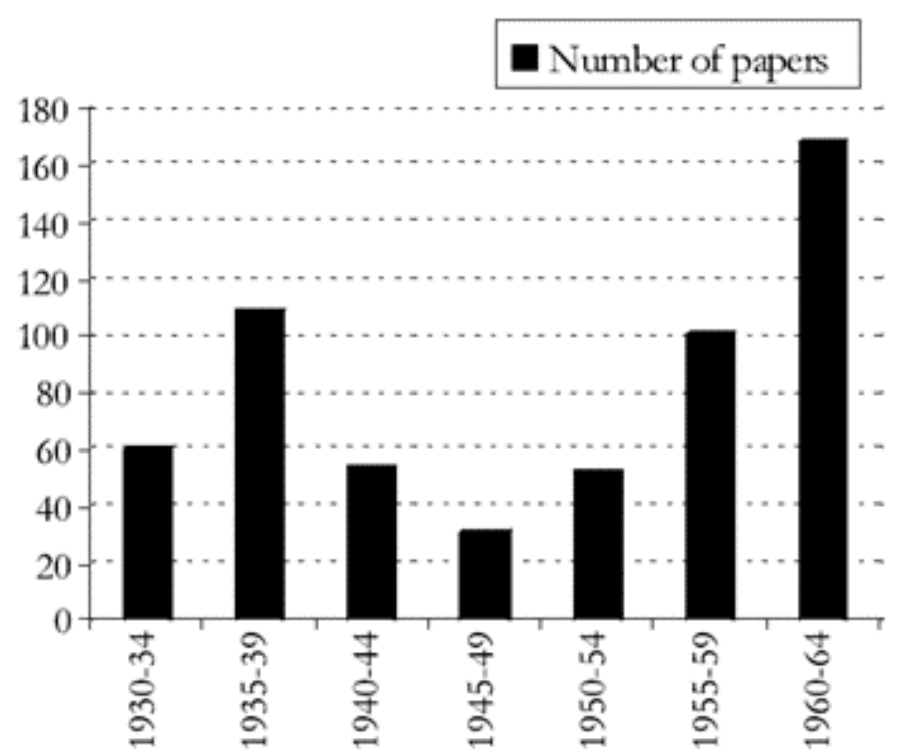

Figure 3. Evolution in the number of psychophysiological reports from 1930 to 1964 . 
Finally, all 576 papers were published in 113 journals, although the distribution was unequal: $63.1 \%$ of the reports appeared in only 15 periodical publications (Table 2 ), whereas only one report per journal was published in another 62 journals. Most of the journals preferred by psychophysiologists to publish their studies were, as expected, in the area of psychology, but those dealing with psychiatry or medicine and with more general topics are also present.

Table 2. Journals Publishing the Greater Number of Psychophysiological Reports during the Period 19301964

\begin{tabular}{lc}
\hline Journal (year founded) & $\begin{array}{c}\text { Number of papers in } \\
\text { psychophysiology }\end{array}$ \\
\hline Journal of Experimental Psychology (1916) & 71 \\
Psychosomatic Medicine (1938) & 43 \\
Science (1883) & 35 \\
Journal of General Psychology (1927) & 29 \\
American Journal of Psychology (1887) & 24 \\
Journal of Comparative and Physiological Psychology (1921) & 22 \\
Electroencephalography and Clinical Neurophysiology (1949) & 22 \\
Archives of General Psychiatry (1959) & 20 \\
American Journal of Psychiatry (1921) & 17 \\
Journal of Psychology (1936) & 16 \\
Archives of Neurology and Psychiatry-Chicago (1919) & 15 \\
Journal of Psychosomatic Research (1956) & 13 \\
Psychological Review (1894) & 13 \\
Journal of Nervous and Mental Disease (1874) & 13 \\
Annals of the New York Academy of Sciences (1877) & 11 \\
\hline
\end{tabular}

\section{Samples}

As would be expected of a discipline in a state of consolidation, concerned with characterizing the variables and processes of interest, most of the samples used in the empirical studies are composed of healthy adult subjects (69.4\%). Second, and according to an important quantity of research on psychopathology and psychophysiological disorders, $22.9 \%$ of the reports assess clinical populations. Only a few studies $(6 \%)$ use samples composed of children, and, finally, a very small group of investigations (1.7\%) are case studies.

\section{Physiological Systems and Recording Techniques}

Figure 4 summarizes the response systems or the type of physiological activity according to the number of publications where they are reported. 


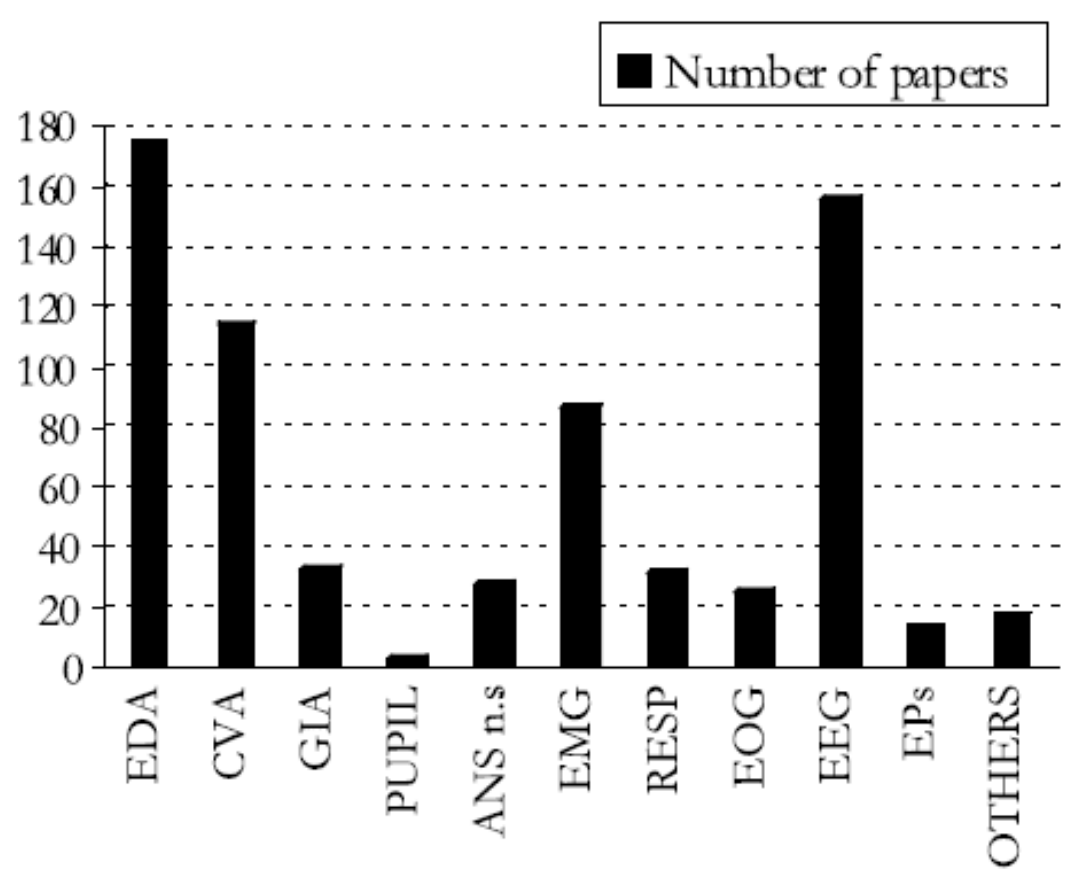

Figure 4. Number of reports that assess each of the physiological response system.

First, it is important to point out that a large number (37\%) of the reports reviewed simultaneously assess two or more psychophysiological variables. The availability of the polygraph as a multichannel recording instrument since the 1930s is, without doubt, the key factor making possible the combined use of different psychophysiological measurements. However, only $9.5 \%$ combined variables from different domains of the nervous system: $5 \%$ assess variables from the autonomic and somatosensory nervous systems simultaneously, $1.9 \%$ combine the autonomic and central nervous systems, $1 \%$ the central and somatosensory nervous systems, and $1.6 \%$ all three domains.

As may be seen, the recording of responses with control of the autonomic nervous system (ANS) was prominent in psychophysiological research between 1930 and 1964. Among these variables regulated by the ANS, electrodermic activity was the most widely studied, present in $30.4 \%$ of the published studies. Thirty-eight of the 66 authors used electrodermic indices as dependent variables in their research. Cardiovascular activity was in second place, present in $19.8 \%$ of the reports. Recordings of cardiac activity, especially heart rate, were present in more than $54 \%$ of the papers dealing with the cardiovascular system. It is not possible to quantify the use of electrocardiography, because the majority of the abstracts in the database do not specify the recording technique. Forty one percent of these publications used blood pressure as the dependent variable, and $43.8 \%$ assessed other responses related to peripheral vascular activity (pulse volume, temperature, pulse amplitude, etc.). Thirty-eight authors also studied cardiovascular responses; 29 of them were coincidental with those who assessed electrodermal activity.

The percentage of studies exploring gastrointestinal activity was lower, only $5.7 \%$, despite the inclusion of the classic studies by Wolf and Wolff measuring gastric 
secretions in patients with gastric fistulas - a procedure that is obviously exceptional in psychophysiology-and also the studies, fundamentally by Razran, using salivation in conditioning paradigms. Only 8 of the 30 reports, all after 1955 and by Davis, Sternbach, and Wenger, used electrogastrography as the recording technique.

Pupillometry occupies a marginal position: After pioneering work by Lindsley, in 1939 , it is not indexed until the classic studies by Hess in the 1960s. Other response systems, such as the sexual system, do not appear in the reviewed reports. Finally, 28 papers using responses with ANS control are unclassified, as the abstracts do not specify the variables studied

Measures and recording techniques related to the somatosensory nervous system had less presence than those related to the ANS. The surface electromyographic recording of muscular activity was used in $15.1 \%$ of the reports. From the 20 authors exploring this response system, the largest number of studies were published by R. C. Davis (22 papers), Malmo (21), and Travis (19). Respiration rate was included in only $5.5 \%$ by 18 authors, and was always assessed jointly with other response systems. The electrooculographic recording of ocular movements was limited to $4.3 \%$ of the papers, most of them related to the study of sleep and authored by Aserinsky, Dement, and Kleitman.

The analysis of central nervous system activity occupied second place, after electrodermal activity. Reports using spontaneous electroencephalography represent $27.1 \%$ of those reviewed, and were presented by 27 authors. Berger (with 13 papers), Darrow (14), Gibbs (16), Jasper (11), Lindsley (14), Loomis (10), Shagass (8), and Travis (12) were the researchers with the largest number of reports dealing with EEG. Another $2.4 \%$ of these studies, published by Dawson, Donchin, Lindsley, Lubin, and Shagass used event-related brain potentials. The technique for recording event-related potentials was incorporated in the 1950s; it was mainly developed after $1964-1965$, and went on to achieve a predominant position in the last decades of the century.

\section{Topics}

The topics of interest in the literature reviewed were classified as shown in Table 3. The category "methodological aspects" comprises studies dealing with the presentation or description of new recording and analysis instruments and procedures. The papers under the heading "psychophysiological signal characterization" are those that focus on the initial descriptions of psychophysiological variables, their dependence on physical conditions, and the determination of their physiological basis. Together, the presence of these two categories $-12.3 \%$ and $18.2 \%$, respectively- clearly shows the stage of the discipline at that time, occupied with laying the foundations for its development. Authors like Berger (13 papers), Darrow (16), Davis (7), Jasper (7), Landis (9), Lindsley (10), or Wilcott (8) made great efforts to characterize psychophysiological variables. Electrodermic and electroencephalographic signals were the main focus of this investigation, with 38 and 51 of the 105 papers, respectively. The most prolific psychophysiologists concerned with the development of methodological aspects of the discipline were Ax (7 papers), Darrow (12), Davis (10), Freeman (4), and Wegner (4). In 
this area, electrodermal and electroencephalographic systems were also the most widely studied. Far from this important amount of production in signal characterization and methodological aspects, the first two papers to offer a conceptual delimitation of the field of psychophysiology only appeared at the end of this period, written by Ax.

Table 3. Topics in the Psychophysiological Papers during the Period 1930-1964

\begin{tabular}{lc}
\hline Topic & $\begin{array}{c}\text { Number of } \\
\text { papers }\end{array}$ \\
\hline Psychophysiological signals characterization & 104 \\
Orientation, habituation, conditioning & 81 \\
Psychopathology & 77 \\
Methodological aspects & 71 \\
Basic concepts & 63 \\
Sleep, rhythms, and altered states of consciousness & 39 \\
Information processing & 31 \\
Individual differences & 29 \\
Psychophysiological disorders and stress & 27 \\
Others & 25 \\
Emotions & 15 \\
Applications & 14 \\
Conceptual delimitation & 2 \\
\hline
\end{tabular}

Another important set of reports are included under the category "basic concepts". They deal with theoretical constructs such as activation, response specificity, law of initial values, or homeostasis, that make it possible to clarify issues related to the functional significance of psychophysiological variables. From the 63 papers included in this category $(11 \%), 34$ deal with the activation concept: physiological characterization, relationships with other variables (sociodemographic, personality traits), and the effect of activation level on execution. R. C. Davis (2 papers), Duffy (3), Freeman (15), Kaplan (3), Malmo (3), and Shapiro (2) were some of the authors interested in this topic, and electrodermal variables were the most widely used measurements. Eleven reports, mainly by B. C. Lacey and J. I. Lacey (5 papers) and Wenger (5), explored the individual stereotypy of response, including relations with personality traits and psychophysiological disorders. Mainly electrodermal and cardiovascular systems were assessed in the study of this construct. Nine studies refer to autonomic balance and homeostasis, and another 8 deal with the law of initial values. Wenger, with 5 papers about autonomic balance, and Wilder, with 3 reports on the law of initial values, were the main authors dedicated to these concepts. The number of studies about activation is on par with the relevance of the theoretical development of this concept in the consolidation of psychophysiology (Thompson \& Robinson, 1979).

Research into orienting, habituation, and conditioning is another of the classic areas of interest in psychophysiology. The variables studied in relation to this topic were mainly those from the electrodermal, cardiovascular, gastrointestinal, and electroencephalographic systems. Eighty-one (14\%) of the reports reviewed are included in this category, most of them (54) dealing with conditioning. About 20 of the authors reviewed published some articles in this area, with Razran as the most important. The study of orienting response and its habituation is the topic of 27 papers, 12 of them 
by Sokolov, and with Darrow (2 papers), R. C. Davis (4), Forbes (3), and Sternbach (3) also interested in this area. It is widely known that the increased interest in orienting response in western psychophysiology dates from 1963, at the end of the studied period, when the book Perception and the Conditioned Reflex by Sokolov (195801963) was translated to English.

The psychophysiological study of psychopathology also had a relevant place in research from 1930 to 1964, with 77 reports (13.3\%), dealing with psychotic and neurotic disorders. The aim of identifying anomalies in physiological responses associated with psychopathological disorders developed together with the refinement of recording procedures and the characterization of responses. The use of psychophysiological variables as indices of activation and the hypothesis of a diathesis to stress in psychophysiological disorders supported a large number of the studies in this area. Twenty-eight authors had publications dedicated to this field, but Malmo was undoubtedly its greatest devotee, with 21 from his 30 publications; others like Darrow (6 papers), Shagass (6) or Venables (6) are also prominent. Electrodermal and electromyographic variables were the most widely studied in this field, with cardiovascular and electroencephalographic variables secondary, although still substantial.

Research into psychophysiological disorders and stress led to a smaller amount of scientific production in this period, 27 papers, where cardiovascular disorders (hypertension, Raynoud disease, arrhythmia, etc.), and subsequently cardiovascular responses, had a relevant position. Six papers dealing with the relationships between psychophysiological disorders and psychopathology, personality variables, or individual response specificity should be added. D. T. Graham and F. K. Graham (7 papers), Wolf (10) and Wolff (4) were some of the authors interested in this area. There are no reports exploring psychophysiological treatment of disorders, an area that would undergo an important development in subsequent decades.

Studies into sleep, rhythms, and altered states of consciousness comprise 39 publications. Most of them (31) deal with the physiological characterization of sleep and dreaming, in terms of electroencephalographic, electromyographic, and electrooculographic measurements; only a few papers assessed autonomic variables. Aserinsky, Dement, and Kleitman, with 14 papers, Loomis, Harvey, and Hobart, with 10, and Lubin, with 5, were the main authors in this field. The rest of the papers deal with biorhythms, sleep deprivation, and altered states of consciousness (hypnosis, meditation).

Interest in information processing was low in comparison to its salience in subsequent years. This category includes research into perception, attention, memory, mental effort, and response processes in healthy subjects. Between 1930 and 1964, screening of the literature resulted in 31 papers, $5.4 \%$ of the total, 13 of them by $\mathrm{R}$. C. Davis. Electromyography was the most prominent technique in this area, followed by cardiovascular responses and electroencephalography. This area would grow in close association with the expansion of the event-related potential recording later. 
With a similar number of reports, the topic of individual differences was present in psychophysiology for the years analyzed, mainly in the area of personality (22 out of 29 papers in this category) and also intelligence. Eighteen of the 66 authors reviewed were interested in individual differences, with Gibbs (4 papers) and Greenfield (3) as the most prolific. Electroencephalographic, electrodermal, cardiovascular, and electromyographic variables were the main measures assessed.

The amount of research published regarding the area of emotions was smaller, with only 15 papers by 10 authors (including Davis, Edelberg, Wolf, and Wolff ) centered on autonomic indices (electrodermal, cardiovascular, and gastrointestinal). This is especially relevant because of the importance of this topic in the first three decades of the century and the presence of chapters devoted to the psychophysiology of emotion in psychology handbooks (e.g., Woodworth, 1938; Lindsley, 1951). The inconsistency of results obtained in those years led to psychophysiological research into emotions being dropped. They would return after 1953, when Ax published the paper "The psychophysiological differentiation of fear and anger in humans."

Finally, applications of psychophysiology other than in clinical treatment were present in the literature reviewed, with 14 papers dealing with the detection of deception and ergonomics. Brozek, Gibbs, Johnson, Lykken, and Orne were some of the authors

working in this area, studying electrodermal, cardiovascular, and electroencephalographic variables.

\section{Conclusions}

The bibliometric study of the published articles of the most prominent psychophysiologists from 1930 to 1964 makes it possible to verify the concurrence of certain traits that characterize a disci pline in a state of consolidation. A small number of publications that -with the exception of the war and postwar period- shows an upwards trend; a predominance of methodological papers, which advanced the standardization of techniques and procedures; an interest in characterizing physiological dependent variables and their relationships with basic psychological processes, or the primacy of empirical studies, with a scarcity of theoretical reviews, are the distinctive features of this 34-year period that culminated with the formalization of the discipline.

It should be noted that the absence of an exhaustive compilation of any other type of scientific production, such as books, doctoral dissertations, or congresses' proceedings, has led us to limit this study to periodical journals. This means that this article offers a partial picture. It is more than likely that some relevant contributions by well-recognized psychophysiologists have been overlooked, but it is possible to get a general sense of the state of the discipline from this review of three decades that were essential for its development.

In the early 1960s, the field of psychophysiology had accumu lated a body of knowledge that was sufficient to lead to its formal constitution as an independent field of research. The main protagonist of this process is, undoubtedly, Albert F. Ax. He made the first attempts to define the discipline, and in 1955, put the Psychophysiological 
Newsletter into circulation, as the first specialized communication medium (Ax, 1964a). In 1960, he headed a group of psychophysiologists, with others such as Chester W. Darrow, Robert Edelberg, John I. Lacey, John A. Stern, and Marion A. Wenger, to form the first scientific society on psychophysiology, the Society for Psychophysiological Research. It brought together scientists interested in this growing area of investigation and in equipment and analytic technique developments, giving them a forum for discussion and interaction. Four years later, in 1964, they started to publish Psychophysiology, which is still the main point of reference for investigations in this area to this day. The subsequent evolution that took place is examined in other reports (e.g., Sánchez-Hernández, Pedraja, Quiñones-Vidal \& MartínezSánchez, 1996).

\section{References}

Ax, A. F. (1953). The physiological differentiation between fear and anger in humans. Psychosomatic Medicine, 15, 433-442.

Ax, A. F. (1964a). Editorial. Psychophysiology, 1, 1-3. Ax, A. F. (1964b). Goals and methods of psychophysiology. Psychophysiology, 1, 8-25.

Berger, H. (1969). On the electroencephalogram of man, I. In P. Gloor (Ed.), Hans Berger on the electroencephalogram of man (EEG suppl. 28, pp. 37-74). Amsterdam: Elsevier. (Original published in 1929)

Brown, C. C. (Ed.). (1967). Methods in psychophysiology. Baltimore, MD: Williams and Wilkins.

Darrow, C. W. (1929a). Differences in the physiological reactions to sensory and ideational stimuli. Psychological Bulletin, 26, 185-201.

Darrow, C. W. (1929b). Electrical and circulatory responses to brief sensory and ideational stimuli. Journal of Experimental Psychology, 12, 267-300.

Darrow, C. W. (1964). Psychophysiology, yesterday, today, and tomorrow. Psychophysiology, 1, 4-7.

Dawson, G. D. (1947). Cerebral responses to electrical stimulation of the waking human brain. Journal of Neurology, Neurosurgery, and Psychiatry, 10, 134-140.

Dawson, G. D. (1954). A summation technique for the detection of small evoked potentials. Electroencephalography and Clinical Neurophysiology, 1, 65-84.

Duffy, E. (1957). The psychological significance of the concept of "arousal" or "activation." Psychological Review, 64, 265-275.

Greenfield, N. S., \& Sternbach, R. A. (1972). Handbook of psychophysiology. New York: Holt, Rinehart and Winston. 
Lacey, J. I., \& Lacey, B. C. (1958). Verification and extension of the principle of autonomic response stereotypy. American Journal of Psychology, 71, 50-73.

Lindsley, D. B. (1951). Emotion. In S. S. Stevens (Ed.), Handbook of experimental psychology (pp. 473-516). New York: John Wiley and Sons.

Malmo, R. B. (1959). Activation: A neurophysiological dimension. Psychological Review, 66, 367-386.

Malmo, R. B., \& Shagass, C. (1949). Physiologic study of symptom mechanisms in psychiatric patients under stress. Psychosomatic Medicine, 11, 25-29.

Niedermeyer, E. (1993). Historical aspects. In E. Niedermeyer \& F. Lopes da Silva (Eds.), Electroencephalography: Basic principles, clinical applications and related fields (3rd ed., pp. 1-14). London: Williams and Wilkins.

PsycINFO (1887-1996) [electronic database]. (1999). Washington, DC: American Psychological Association.

Sánchez-Hernández, A., Pedraja, M. J., Quiñones-Vidal, E., \& MartínezSánchez, F. (1996). A historic-quantitative approach to psychophysiological research: The first three decades of the journal Psychophysiology (1964 -1993). Psychophysiology, 33, 629- 636 .

Sokolov, E. N. (1963). Perception and the conditioned reflex. New York: Plenum Press. (Original published in 1958)

Stern, J. A. (1964). Toward a definition of psychophysiology. Psychophysiology, 1, 90 91.

Sternbach, R. A. (1966). Principles of psychophysiology. An introductory text and readings. New York: Academic Press.

Sutton, S., Braren, M., Zubin, J., \& John, E. R. (1965). Evoked potential correlates of stimulus uncertainty. Science, 150, 1187-1188.

Thompson, R. F., \& Robinson, D. N. (1979). Physiological psychology. In H. Hearst (Ed.), The first century of experimental psychology (pp. 407-457). Hillsdale, NJ: Lawrence Erlbaum Associates.

Venables, P. H., \& Christie, M. J. (Eds.). (1975). Research in psychophysiology. New York: John Wiley and Sons.

Walter, W. G., Cooper, R., Aldridge, V. J., McCallum, W. C., \& Winter, A. L. (1964). Contingent negative variation: An electrical sign of sensorimotor association and expectancy in the human brain. Nature, 203, $380-384$.

Woodworth, R. S. (1938). Experimental Psychology. New York: Henry Holt. 